\title{
Efeito do termoprocessamento sobre o peso e a qualidade interna de ovos inteiros
}

\section{Effect of thermical treatment on weight and internal quality of shell eggs}

\author{
Carolina Riscado Pombo, ${ }^{*}$ Sérgio Borges Mano, ${ }^{* *}$ Valéria Moura de Oliveira, ${ }^{* \star *}$ José Carlos Albuquerque do Prado Carvalho, ${ }^{\star \star *}$ \\ Maria Carmela Kasnowski, ${ }^{* * *}$ Edivaldo Sampaio Filho***
}

\begin{abstract}
Resumo
Este estudo objetivou avaliar possíveis alterações nos fatores de qualidade interna de ovos inteiros, submetidos ao tratamento térmico em banho-maria a $57^{\circ} \mathrm{C}$ por 10 ou 20 minutos, e compara com ovos não submetidos ao termoprocessamento. Foram utilizados 306 ovos divididos em três grupos de 102 ovos cada, sendo dois submetidos ao tratamento e um grupo mantido como controle. Os ovos foram mantidos à temperatura ambiente, e, de cada grupo, retiradas amostras para análise durante os 24 dias do estudo. As análises periódicas foram realizadas no Laboratório de Tecnologia Aves e Derivados da Universidade Federal Fluminense e permitiram avaliar a perda de peso, unidade Haugh, câmara de ar, pH da clara, pH da gema e índice da gema. A análise estatística constou de análise descritiva simples. Os resultados da unidade Haugh revelaram uma ligeira estabilidade na tendência da curva dos ovos submetidos ao termoprocessamento por 20 minutos, apresentando valor médio inicial 81 e chegando ao valor 75 no dia 23, enquanto na curva de tendência do grupo controle a queda foi bem mais acentuada, iniciando com o valor de 90 e chegando ao valor de 19 no dia 23. De acordo com os resultados obtidos, pôde-se concluir que os ovos submetidos ao tratamento com temperatura de $57^{\circ} \mathrm{C}$ por 20 minutos apresentaram maior estabilidade nas características relativas à sua qualidade interna, podendo ser considerado um método de interesse para as indústrias de ovos que primam pela manutenção da qualidade dos produtos oferecidos à população em geral, que, segundo Rodrigues e Salay (2001), adquirem os ovos principalmente nos supermercados nas condições de temperatura ambiente.
\end{abstract}

Palavras-chave: tratamento térmico, ovos, qualidade interna.

\begin{abstract}
The purpose of this study was evaluate the internal quality of shell eggs thermically processed (water bath at $57^{\circ} \mathrm{C}$ ) during a period of time of both 10 and 20 minutes, through the comparison with other eggs which have not been submitted to thermoprocessing (control group). Were used 306 eggs during a period of 24 days and being maintained at the local temperature. Samples of eggs of each treatment were periodically evaluated as to testing loss of weight, unit Haugh, air chamber, white $\mathrm{pH}$, yolk $\mathrm{pH}$ and yolk index. The statistic analysis consisted of a simple descriptive analysis. The results of the Haugh unit described a small stability in which refers the trend of the eggs being submitted to the thermoprocessing during 20 minutes, which showed an initial medium value equal to 81 and even reaching 75 on the 23rd day, while in the trending curve of the control showed a more significant fall, beginning with the value 90 and even reaching 19 on the 23 rd day. According to the results obtained, we might come to the conclusion that the eggs submitted to a temperature of $57^{\circ} \mathrm{C}$ during 20 minutes maintained the characteristics related to the internal quality, with better results during the whole period of the experiment.
\end{abstract}

Keywords: thermical treatment, eggs, internal quality.

\section{Introdução}

O ovo, devido ao seu elevado valor nutritivo é considerado um alimento básico na alimentação humana. Admite-se que a intensa industrialização da avicultura ocorrida nos últimos 30 anos tenha tornado os ovos e a carne de frango, produtos acessíveis a uma crescente população de consumidores (Mulder, 1997).
Os ovos são utilizados como ingredientes em grande parte dos produtos alimentícios, pois, quando batidos, formam uma película que ajuda a incorporação de ar e fornecem as características desejáveis de textura e aparência, principalmente de bolos, merengues e suflês. O ovo é o único alimento que apresenta características polifuncionais - poder de coagulação, capacidade de formação de espuma e propriedades de gelatinização e emulsificação - desejáveis

* Programa de Pós-Graduação em Medicina Veterinária (Mestrado) - Higiene Veterinária e Processamento Tecnológico de Produtos de Origem Animal. E-Mail: carolpombo@yahoo.com.br

** Departamento de Tecnologia dos Alimentos da Faculdade de Veterinária - Universidade Federal Fluminense - Niterói-RJ. Rua Vital Brazil Filho, 64 - 24230-340.

*** Programa de Pós-Graduação em Medicina Veterinária (Doutorado)- Higiene Veterinária e Processamento Tecnológico de Produtos de Origem Animal. Faculdade de Medicina Veterinária, Universidade Federal Fluminense.

Autor para correspondência: Sérgio Borges Mano. E-mail: mtasbm@vm.uff.br. 
em muitos alimentos, tais como produtos de padaria, biscoitos e derivados de carne (Mine, 1995).

Do total da produção de ovos de galinhas no Brasil, apenas $5 \%$ é destinado ao processamento industrial. Subentendese, então, que $95 \%$ da produção total vai para o consumo in natura. Assim sendo, as condições de tempo e a temperatura no armazenamento desses ovos são essenciais para garantir a boa qualidade do produto. E por serem embalados naturalmente, a qualidade se torna visível somente quando o comprador for utilizá-los (Smith e Nguyen, 1984).

Segundo Flores et al. (2001), estimativas brasileiras citam 34 mil pessoas envolvidas anualmente em surtos de intoxicações alimentares causadas por Salmonella spp. Freqüentemente ovos ou produtos deles derivados, como cremes, maio-nese e clara batida fresca, são indicados como fontes de infecção.

Não foram encontradas referências relativas à pesquisa de efeitos do tratamento térmico sobre as características de qualidade interna de ovos inteiros após a postura. Tais considerações sugerem a necessidade de um maior conhecimento sobre a qualidade dos ovos oferecidos ao consumo, bem como das modificações sofridas durante o período de conservação. Neste estudo objetivou-se avaliar as possíveis alterações nos indicadores de qualidade interna de ovos inteiros após o termoprocessamento.

\section{Material e métodos}

Foram utilizados 306 ovos de um mesmo lote e recém-postos, oriundos de uma granja localizada no município de São José do Vale do Rio Preto, localizado no estado do Rio de Janeiro. As poedeiras eram da linhagem Lohmann LSL e da mesma idade.

Os ovos foram acondicionados em alvéolos com capacidade para 30 ovos e transportados em caixas de papelão para o Laboratório de Tecnologia de Aves e Derivados do Departamento de Tecnologia de Alimentos da Faculdade de Veterinária da Universidade Federal Fluminense onde foram termicamente processados e analisados seguindo o protocolo.

Nas condições de laboratório, os ovos foram divididos em três grupos de 102 ovos cada, sendo dois grupos submetidos ao termoprocessamento (grupos A e B) por tempo de 10 ou 20 minutos, e um grupo que não foi submetido ao tratamento térmico sendo este o contole (Grupo $\mathrm{C}$ ). os três grupos foram mantidos na temperatura ambiente durante os 24 dias de realização do estudo.

O tratamento térmico consistiu na manutenção dos ovos do grupo A em banho-maria (Thermomix ${ }^{\circledR} \mathrm{BM}$, modelo Frigomix ${ }^{\circledR}$ B) em temperatura de $57^{\circ} \mathrm{C}$ por 10 . Os ovos do grupo B foram mantidos na mesma temperatura, mas por um tempo de 20 minutos. Em seguida, os ovos foram mantidos na temperatura ambiente onde secaram naturalmente.

De cada grupo ( $A, B$, e $C$ ) foram retiradas amostras de seis ovos que foram analisadas quanto à unidade Haugh, tamanho da câmara de ar, valores de $\mathrm{pH}$ da clara e da gema e índice da gema. As análises foram feitas a cada 24 horas nos primeiros 10 dias do estudo e a cada 48 horas nos 14 dias subseqüentes.

A pesagem dos ovos foi realizada, individualmente, em balança analítica e a mensuração do tamanho da câmara foi realizada através de observação individual ao ovoscópio. A demarcação da câmara de ar foi feita com auxílio de um lápis e sua altura foi medida em escala milimétrica de $15 \mathrm{~mm}$.

Para a análise da qualidade interna, os ovos foram quebrados sobre uma mesa de vidro apropriada, provida de espelho na parte inferior e a altura da clara densa foi então medida com auxílio de micrômetro. Nessa mesma mesa, a altura da gema foi medida com auxílio de micrômetro e o diâmetro foi determinado pela utilização do paquímetro. Em seguida o ovo foi deslocado da mesa de vidro com um pequeno rodo, até o separador de gemas.

Após a separação da gema e clara, as medidas de $\mathrm{pH}$ foram tomadas com o uso de um medidor de $\mathrm{pH}$ da marca Horiba, modelo M13.

A análise estatística realizada no presente estudo constou de análise descritiva simples.

\section{Resultados e discussão}

Os resultados demonstrados nos gráficos da Figura 1 indicam que há um aumento constante dos percentuais de perda de peso, alturas das câmaras de ar e pH da clara durante os 24 dias de armazenamento em ambos os tratamentos e no grupo controle. No que se refere ao $\mathrm{pH}$ da gema, observou-se uma relativa estabilidade, variando de 6,1 no dia zero a 6,5 no dia 23 , sem diferenças significativas entre os três grupos de ovos que foram analisados.

Segundo Stadelman e Cotterill (1994), o ácido carbônico, um dos componentes-tampão do albúmen, dissocia-se, formando água e gás carbônico. Sob condições naturais, o gás carbônico formado se difunde através da casca e se perde no ambiente. Segundo os mesmos autores, devido à libertação do gás carbônico, diminui a acidez do albúmen, incidindo no aumento de $\mathrm{pH}$ e a dissociação química do complexo protéico. Durante o armazenamento, esta perda do dióxido de carbono e de umidade ocorrida através das membranas e da casca leva ao aumento constante dos percentuais de perda de peso e dos valores das alturas das câmaras de ar. Cheftel (1989) e Solomon (1997) confirmam tais resultados explicando que, durante o armazenamento, ocorre perda de água (gerando a perda de peso) e dióxido de carbono através das membranas e da casca e, por isso, a câmara de ar aumenta em conseqüência da entrada de gases.

Em relação ao índice da gema, ocorreu uma diminuição constante nos valores médios: que a partir do sétimo dia, os ovos termoprocessados por 20 minutos apresentaram valores médios maiores do que os controles e os submetidos ao tratamento térmico por 10 minutos. De acordo com Cheftel et al. (1989) e Romanoff e Romanoff (1949), com o passar do tempo, a água migra do albúmen para a gema, o que faz com que ocorra um alargamento e um achatamento da gema Esta migração resulta no estiramento e fragilidade da membrana vitelina justificando os resultados observados no estudo.

Ao longo do estudo foi observado que o lote submetido a $57^{\circ} \mathrm{C}$ por 20 minutos apresentou maior estabilidade protéica. Com isso, ocorreu uma menor alteração conformacional da gema levando a menor queda dos valores médios de índice da gema. 

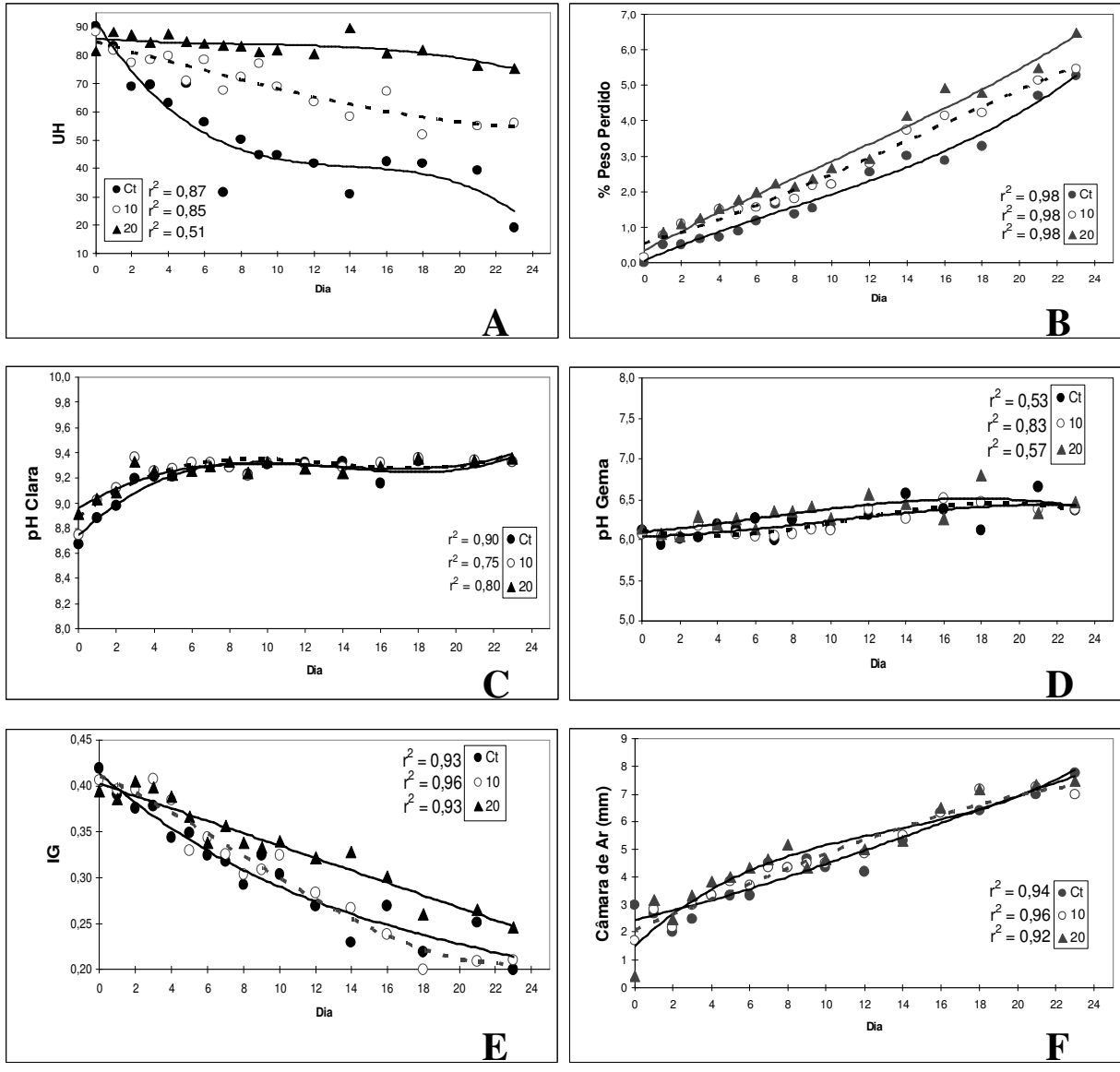

Figura 1: Representação gráfica dos valores médios e suas respectivas linhas de tendência e coeficiente de correlação $\left(r^{2}\right)$ dos ovos de galinha submetidos à temperatura de $57^{\circ} \mathrm{C}$ por 10 e 20 minutos durante 24 dias. Cl: Grupo Controle; (A) Unidade Haugh; (B) Percentual de peso perdido; (C) $\mathrm{pH}$ da clara; (D) pH da gema; (E) Índice da gema; e (F) Câmara de ar (mm).
Foi observado para os resultados da unidade Haugh uma ligeira estabilidade na tendência da curva dos ovos submetidos ao termoprocessamento por 20 minutos, apresentando valor médio inicial 81 e chegando ao valor 75 no dia 23 , enquanto na curva de tendência do controle apresentou uma queda bem mais acentuada, iniciando com o valor de 90 e chegando ao valor de 19 no dia 23. A linha de tendência dos ovos submetidos à temperatura de $57^{\circ} \mathrm{C}$ por 10 minutos sofreu uma queda menos intensa que a citada anteriormente, variando de 88 no dia zero para 56 no dia 23.

Cheftel et al. (1989) afirmam que um tratamento a $58^{\circ} \mathrm{C}$ durante 2 minutos já provoca a desnaturação-insolubilização da conalbumina e um forte aumento da viscosidade. Os ovos tratados termicamente por 20 minutos obtiveram valores médios maiores que os tratados por 10 minutos e os controle, demonstrando uma maior estabilidade das proteínas. Uma vez que os resultados da unidade Haugh são justificados pela correlação entre altura da clara densa e peso dos ovos, a estabilidade protéica é um fator importante a ser destacado nesta avaliação, explicando os resultados apresentados.

\section{Conclusão}

De acordo com os resultados obtidos no presente trabalho, pode-se concluir que os ovos submetidos à temperatura de $57^{\circ} \mathrm{C}$ por 20 minutos mantiveram as características relativas

\section{Referências}

CHEFTEL, J.C.; CUQ, J.L.; LORIENT, D. Proteínas Alimentarias. Zaragoza: Acribia, 1989. cap. 6. p. 167-177.

FLORES, M.L.;SILVA, J.H.S.;NASCIMENTO, V.P.; KADER, IIIT.A.;SANTOS, L. R.; PONTES,A.P.; SALLE, C.T.P.; LOPES, R.F.F. Detecção de Salmonella sp em ovos de galinhas através da reação em cadeia pela polimerasePCR. Higiene Alimentar, São Paulo, v. 15, n. 80/81, p. 63-68, 2001.

Mine, Y. Recents advances in the understanding of egg white protein functionally. Trends in food sci. and technol., v. 6, p. 225, 1995.

MULDER, R.W. Safe poultry meat production in the nest century. Acta. Vet. Hung., v. 43, p. 307-315, 1997. à qualidade interna com melhores resultados durante todo período do experimento. Sugere-se o desenvolvimento de estudos microbiológicos em função do tratamento térmico para a observação de possíveis melhorias nos processos de conservação.

RODRIGUES, K.R.M.; SALAY, E. Atitudes de granjeiros, atacadistas, varejistas e consumidores em relação à qualidade sanitária do ovo de galinha in natura. Rev. Nutr., Campinas, v. 14, n. 3, p 185-193, 2001.

ROMANOFF, A.L.; ROMANOFF, A. J. The avian egg. New York: John Wiley and Sons, 1949. 553 p.

SMITH, M.B.; NGUYEN, L. Measuring the age of stored eggs. CSIRO Food Res. Q. 44, 94, 1984.

SOLOMON, S.E. Egg and Eggshell Quality. lowa: lowa State University Press, 1997. $149 \mathrm{p}$.

STADELMAN, W.J., COTTERILL, O.J. Egg Science and Technology. 4. ed. New York: The Haworth Press, 1994. 591 p. 